\title{
AS LÓGICAS DOS TERMOS SINGULARES
}

\section{Newton Marques Peron ${ }^{1}$}

\begin{abstract}
RESUMO
A partir de meados do século XIX, os termos singulares passaram a ter um papel crucial na filosofia da lógica e da linguagem. Este artigo se debruça sobre alguns problemas envolvendo termos singulares em cinco autores: Frege, Russell, Strawson, Kripke e Kaplan. Busco aqui, primeiramente, compreender de que modo a lógica desses filósofos está em consonância ou não com sua filosofia da linguagem no que diz respeito aos termos singulares. Como argumentarei no presente artigo, há três filósofos em que há uma dissintonia entre lógica e filosofia da linguagem: Frege, Strawson e Kaplan. No caso de Frege, analiso a proposta de Lehmann de uma lógica da filosofia da linguagem e concluo que ela é bastante adequada à visão fregeana. Nos casos de Strawson e Kaplan, defendo que as propostas existentes na literatura são inadequadas, e proponho uma alternativa de lógica da filosofia da linguagem para cada um desses dois filósofos. Por fim, esboço uma solução que consiste numa combinação de três tipos de lógica, de modo que tal combinação acomodaria grande parte das filosofias da linguagem quanto aos termos singulares dos cinco filósofos aqui tratados. Essa solução, além disso, dá conta de alguns problemas concernentes ao uso de nomes próprios em contextos ficcionais, algo que as abordagens dos filósofos acima listados deixam a desejar.
\end{abstract}

Palavras-chave: Termos Singulares. Nomes Próprios. Descrições Definidas. Nomes Ficcionais.

\begin{abstract}
Since the middle of the 19th century, singular terms started to play a crucial role in the philosophy of logic and language. This paper focuses on some problems pertaining singular terms in five authors: Frege, Russell, Strawson, Kripke and Kaplan. Firstly, I try here to understand how the logic of those philosophers is or not in line with their philosophy of language concerning singular terms. As I will argue in this paper, there are three philosophers in which there is a disagreement between logic and philosophy of language: Frege, Strawson and Kaplan. In Frege's case, I analyze Lehmann's proposal for a logic of the philosophy of language and conclude that it is quite adequate to the Fregean view. In Strawson's and Kaplan's cases, I argue that the

${ }^{1}$ Professor permanente do Programa de Pós-Graduação em Filosofia da UFFS (Universidade Federal da Fronteira Sul), campus Chapecó.

E-mail: newton.peron@uffs.edu.br. ORCID: 0000-0003-3724-1775.
\end{abstract}


existing proposals in the literature are inadequate, and I propose an alternative logic of the philosophy of language for each of these two philosophers. Finally, I outline a solution that consists of a combination of three types of logic, so that such a combination would accommodate much of the philosophies of language regarding the unique terms of the five philosophers that are treated here. Moreover, this solution addresses some problems concerning the use of proper names in fictional contexts, something that the approaches of the philosophers listed above are found wanting.

Keywords: Singular Terms. Proper Names. Definite Descriptions. Fictional Names.

\section{Introdução}

Por mais de dois milênios, a lógica e a filosofia deram pouca importância aos denominados termos singulares. São exemplos de termos singulares: nomes próprios como "Sócrates", pronomes demonstrativos seguidos de termos gerais como "este filósofo" e descrições definidas como "o mestre de Platão".

Foi apenas em meados do século XIX, com os trabalhos de Frege, que os termos singulares passaram a ter um destaque especial na lógica e na filosofia da linguagem. Essa polêmica permeou grande parte do debate na filosofia analítica ao longo do século XX. Neste artigo, vamos nos concentrar em alguns desses debatedores, como Russell, Strawson, Kripke e Kaplan.

Com o intuito de apresentar de maneira esquemática a articulação entre lógica, filosofia da linguagem e termos singulares em cada um desses filósofos, consideraremos a classificação de Morris (2007, p. 69). Para o autor, com relação à articulação entre lógica e filosofia da linguagem na tradição analítica, há dois grandes grupos de filósofos.

O primeiro grupo vê o papel do filósofo como alguém que cria uma linguagem artificial para, a partir dela, erigir sua filosofia da linguagem. Esse grupo vê a linguagem humana como uma maquinaria complexa, cabendo ao filósofo desvendar o seu funcionamento. Nesse grupo, não há distinção entre filosofia da linguagem e lógica. Nesse artigo, pretendo apresentar boas razões para incluir nesse primeiro grupo Russell, Kripke e Kaplan. 
Um segundo grupo, porém, é relutante em generalizar a riqueza da linguagem natural por meio de qualquer linguagem formal. Para esse grupo, a filosofia da linguagem não consiste em apresentar os mecanismos intrínsecos da linguagem natural por meio de um modelo formal, mas sim em compreender o que as pessoas fazem quando usam a linguagem. Aqui, o divórcio entre lógica e filosofia da linguagem é bastante natural e, acrescentaríamos, até esperado. Há, acredito, bons motivos para incluirmos Frege e Strawson nesse segundo grupo.

A divergência entre os dois grupos é muito menor, porém, do que a princípio possa parecer. Se entendermos algumas lógicas como um modelo formal para o papel dos termos singulares na filosofia da linguagem desses filósofos, teríamos - com todas as ponderações que devemos ter face a qualquer tabela esquemática em filosofia - a seguinte tabela:

\begin{tabular}{|c|c|}
\hline Filosofia da Linguagem & Lógica dos termos singulares \\
\hline Frege & Lógica Livre Neutra \\
\hline Russell & Lógica Clássica \\
\hline Strawson & Lógica Livre Neutra \\
\hline Kripke & Lógica Modal Clássica \\
\hline Kaplan & Lógica Híbrida Clássica. \\
\hline
\end{tabular}

Até agora, porém, não foi proposta nenhuma Lógica Híbrida Livre. Essa lógica, creio eu, com algumas adaptações pode ser entendida como um modelo formal capaz de acomodar grande parte das posições de Frege, Strawson, Kripke e Kaplan com relação aos termos singulares.

Acredito que podemos defender uma filosofia da linguagem que brote desse modelo formal e que não seja classificada em nenhum dos dois grupos descridos por Morris. Diferentemente de Russell, Kripke e Kaplan, que propõem uma interpretação definitiva dos termos singulares na linguagem natural que forçosamente se acomode a certo modelo formal ideal, defendo uma filo- 
sofia da Lógica Híbrida Livre como uma maneira de produzir uma semântica formal que seja um mero modelo temporário para compreender um certo uso dos termos singulares na linguagem natural.

Além disso, nessa perspectiva não haveria um divórcio entre lógica e filosofia da linguagem, como há em Frege e Strawson. Mas isso porque a lógica não teria apenas o papel normativo de nos impor como devemos raciocinar, como é o caso da Lógica Clássica. No meu entender, a lógica tem muitos papéis e, dentre eles, o papel de fornecer um modelo - simplista e reducionista, como qualquer modelo - para compreender melhor um aspecto do que as pessoas fazem quando usam os termos singulares na linguagem natural.

\section{Termos Singulares e a Revolução Fregeana}

O conceito de termo singular nos remete à Grécia Antiga. Aristóteles, por exemplo, distingue em Da Interpretação (17a37-17b16) termos singulares de termos gerais. Os exemplos de Aristóteles para termos singulares são "Sócrates" e "este homem", que buscam se referir a um único indivíduo. Termos gerais são "homem" e "branco", que não se referem a um indivíduo particular, mas que buscam apreender certas características gerais de certos indivíduos.

Em Primeiros Analíticos (24a10-24a15), fica claro que a preocupação maior de Aristóteles não é o estudo das regras que formam as sentenças, mas certos tipos específicos de sentença: as proposições (protasis). Grosso modo, para Aristóteles proposições são sentenças que podem ser verdadeiras ou falsas. Mas dentre as proposições, apenas as proposições em que ocorrem somente termos gerais recebem sua atenção especial.

Tendo isso em vista, podemos nos arriscar a dizer que aquilo que posteriormente ficou conhecido como lógica aristotélica tinha como objeto de estudo sobretudo os termos gerais. Desse modo, durante séculos a distinção entre termos gerais e termos singulares tinha a função primordial de alertar que o objeto de investigação lógica no que concerne às partes da proposição deixaria em segundo plano os termos singulares.

Uma grande revolução ocorreu quando Frege, em Fundamentos da Aritmética, passou a defender que a análise lógica não deve se restringir aos 
termos gerais, mas que devemos levar em conta também os termos singulares. $\mathrm{Na}$ verdade, essa mudança de enfoque é o reflexo linguístico de um abismo lógico aberto por Frege entre conceitos e objetos (1974, p. 202).

Enquanto o conceito é a referência (Bedeutung) de um termo geral (FREGE, 2009, p. 168), os termos singulares têm objetos como referência. Frege sustenta que, por um lado, há modos distintos de se referir a um mesmo objeto e, por outro, que a noção de objeto é muito ampla, de modo a abarcar não apenas indivíduos e objetos da nossa percepção sensível, mas também objetos não espaciais. Como exemplo de objetos não espaciais temos os números, que são objetos matemáticos (FREGE, 1974, p. 253 ). ${ }^{2}$ É digno de menção que termos singulares abarcam não apenas nomes próprios, como “Aristóteles”, mas também descrições definidas, como "o discípulo de Platão e mestre de Alexandre Magno”. (FREGE, 2009, p. 132).

Como bem observou Frege, não há uma correspondência biunívoca nas linguagens naturais - como o alemão ou o português - entre termos singulares e objetos. Em outras palavras, não é verdade que nessas linguagens para cada objeto há um único termo singular que se refira a ele. De fato, podemos ter dois termos singulares se referindo a um único objeto. Esse é o caso dos termos singulares "a estrela da manhã" e "a estrela da tarde", que se referem ao mesmo objeto celeste, que é o planeta Vênus (FREGE, 2009, p. 131). Tampouco é verdade nessas linguagens que todo termo singular tem ao menos um objeto como sua referência. O termo singular "o corpo celeste mais distante da Terra", por exemplo, não se refere a objeto nenhum (FREGE, 2009, p. $133)$.

O fenômeno de termos singulares sem referência é mais evidente se olharmos para nomes próprios em contextos ficcionais, como "Ulisses". Visto que o personagem Ulisses da Ilíada e da Odisseia nunca existiu, "Ulisses" é um termo singular sem referência. Mas Frege explica que quando lemos lite-

\footnotetext{
${ }^{2}$ Estamos aqui excluindo e o Verdadeiro e o Falso, que são objetos lógicos (FREGE, 2009, p. 139). A razão disso é que o que estamos usando aqui a expressão "termos singulares" para englobar nomes próprios genuínos e descrições definidas, ou seja, partes de uma sentença, enquanto o Verdadeiro e o Falso são a referência de uma sentença assertiva completa (FREGE, p. 138). Outro modo de entender os termos singulares na linguagem natural em Frege é considerá-los como sendo tudo aquilo que é um nome de um objeto, excluindo-se o Verdadeiro e o Falso.
} 
ratura, não estamos preocupados se Ulisses de fato existiu ou não e a questão da verdade ou falsidade das sentenças sequer se coloca. Quando, por outro lado, passamos a ter uma atitude de investigação científica, o valor de verdade da sentença passa a ter importância fundamental. Aí é importante garantirmos que cada termo singular tenha, ao menos, uma referência (FREGE, 2009, p. 137-138).

De acordo com Frege, se uma das partes de uma sentença assertiva completa não tem referência, a sentença como todo não pode ser considerada nem verdadeira nem falsa, ou seja, a sentença também não tem referência (2009, p. 138). ${ }^{3}$ Esse princípio é conhecido na literatura como Princípio Compositivo (Principle of Compositionality), e pode ser anunciado do seguinte modo:

Princípio Compositivo (PC): O valor semântico de uma expressão complexa depende do valor semântico de todas as expressões mais simples que ocorrem nela e do modo como essas expressões estão combinadas. $^{4}$

\footnotetext{
${ }^{3}$ Para Frege, "sentenças assertivas completas" se referem ao Verdadeiro ou ao Falso e, portanto, essas sentenças poderiam ser entendidas como "nomes" desses objetos. Isso é o que aparece indicar em Digressões Sobre o Sentido e Referência (2009, p. 160): "Um nome próprio tem como referência o objeto que ele designa ou nomeia". Mas isso não valeria para qualquer sentença. Mesmo num contexto em que todos os termos singulares que ocorrem numa determinada sentença tenham referência, a sentença como um todo pode não se referir a um valor de verdade, por exemplo, se estamos diante de uma sentença subordinada. Nesse caso, a sentença pode se referir a um pensamento, a pedaços de pensamentos ou até mesmo a um indivíduo (2009, p. 142). No primeiro caso, Frege cita como exemplo a sentença "Copérnico acredita que as órbitas planetárias eram circulares". Aqui, a subordinada "que as órbitas planetárias eram circulares" não se refere a um valor de verdade (no caso, o falso, visto que as órbitas planetárias são elípticas), mas se refere a um pensamento de Copérnico: sua crença (equivocada) de que elas eram circulares (2009, p. 146). Já na sentença "Quem descobriu a forma elíptica das órbitas planetárias morreu na miséria", a subordinada "quem descobriu a forma elíptica das órbitas planetárias" não se refere a um pensamento nem a um valor de verdade, mas um indivíduo; nesse caso, a Kepler (2009, p. 146).

${ }^{4}$ Há diversas versões desse princípio na literatura. A versão aqui apresentada é uma adaptação da Compositionality da Stanford Encyclopedia of Philosophy. O autor da entrada, Szabó, usa o termo meaning, que deve ser melhor traduzido por "significado" (SZABÓ, 2020). Podemos entender, porém, o termo inglês meaning como englobando tanto o conceito fregeano de sentido (Sinn) como de referência (Bedeutung). De certo modo, há duas versões de PC endossadas por Frege: uma no que diz respeito ao sentido e outra no que diz respeito à refe rência. Formulamos aqui uma versão mais neutra do princípio por meio da expressão "valor semântico". Nossa intenção é compreender de que modo esse princípio pode ser ou não verificado nos demais filósofos tratados neste artigo, com visões semânticas distintas.
} 
Isso significa que, no uso científico da linguagem, é importante que os termos singulares se refiram a objetos realmente existentes. Se isso acontecer, então podemos nos assegurar que as sentenças em que ocorrem esses termos singulares são verdadeiras ou falsas. ${ }^{5}$ Não há nada na linguagem natural, porém, que garanta que os termos singulares se refiram a objetos realmente existentes.

A maneira de contornar essa debilidade das linguagens naturais no uso científico é criando uma nova linguagem, uma linguagem artificial. Eis a proposta fregeana: criar uma linguagem escrita de sinais, uma Conceitografia (Begriffsschrift). Nessa nova linguagem, todos os termos terão referência (FREGE, 2009, p. 132) e, portanto, toda sentença escrita nessa linguagem será ou verdadeira ou falsa. ${ }^{6}$

Em termos lógicos, essa linguagem deve respeitar ao menos dois preceitos:

P1 Toda sentença é verdadeira ou falsa, não podendo ser atribuídos a cada sentença ambos os valores de verdade ou nenhum;

P2 Todo termo singular se refere a um único objeto.

\footnotetext{
${ }^{5}$ Essa implicação é imprecisa. Além dos termos singulares terem referência, precisamos que os conceitos também tenham referência. Mas é importante ressaltar que algo diferente ocorre com os conceitos. Por exemplo, o termo singular "Pégasos" não tem referência porque Pégasos não existe. Mas o conceito "cavalo alado" tem referência e, como não existem cavalos alados, o conceito "cavalo alado" tem como extensão o conjunto vazio ou, em outras palavras, a função conceitual cavalo_alado(x) é falsa para qualquer valor de $\mathbf{x}$. Para Frege, conceitos sem referência são conceitos imprecisos. Sobre conceitos vazios, ver, por exemplo, trecho de Os Fundamentos da Aritmética (1974, p. 262) em que se discute o conceito vazio "ser diferente de si mesmo"; sobre conceitos imprecisos, consultar Digressões sobre Sentido e Referência (2009, p. 166).

${ }^{6}$ A Conceitografia é uma linguagem escrita para expressar sentenças assertivas completas. Nessa linguagem, se duas sentenças contém o mesmo conteúdo conceitual, elas são indiscerníveis. Ela não distingue, por exemplo, as sentenças "Em Plateia, os gregos derrotaram os persas" e "Em Plateia, os gregos foram derrotados pelos persas". Além disso, na linguagem da Conceitografia todas as sentenças são consideradas nomes próprios. Isso é possível porque, por exemplo, em vez de se dizer "Aristóteles morreu em Siracusa" pode-se expressar o mes mo conteúdo conceitual dizendo-se "A morte de Aristóteles em Siracusa é um fato". Na linguagem criada por Frege, o único predicado comum a todas as sentenças é o símbolo $\vdash$, para marcar que a sentença formalizada que segue à direta do símbolo foi asserida (2012, p. 5961). Ter uma linguagem constituída apenas de nomes próprios que se referem ao Verdadeiro ou ao Falso e sem distinção de conteúdo conceitual não são as únicas vantagens de uma Conceitografia. Em Sobre a Justificação Científica de Uma Conceitografia, Frege defende que, embora mais rica para outras finalidades, a linguagem natural falada contém uma variedade de modulações que são irrelevantes para o rigor das cadeias dedutivas. Outra vantagem da lin-
} 
Vamos usar aqui a expressão "lógica do tipo clássico" num sentido bem amplo e grosseiro, de modo que definiremos lógica do tipo clássico como sendo toda linguagem artificial que respeite P1, P2 e PC. Nesse sentido lato, a Conceitografia é claramente uma lógica do tipo clássico.

Frege, porém, defende que P1 e P2 não são respeitados nas linguagens naturais. Na verdade, se admitirmos o Verdadeiro e o Falso com sendo referências das sentenças e, ao mesmo tempo, aceitarmos $\mathbf{P C}$, temos que toda linguagem que não respeitar $\mathbf{P 2}$ também não respeitará P1. E, pela ocorrência de termos ficcionais, é evidente que as linguagens naturais não respeitam P2 e, portanto, também não respeitam $\mathbf{P 1}$.

\subsection{A Lógica da Filosofia da Linguagem de Frege}

Considerando que na visão de Frege as linguagens naturais não respeitam P1 e P2, é fácil concluirmos que a lógica das linguagens naturais de Frege não é uma lógica do tipo clássico em sentido amplo. Qual seria, pois, a lógica das linguagens naturais do ponto de vista da filosofia da linguagem de Frege? Segundo Lehmann, em seu artigo Strict Fregean Free Logic, a lógica das linguagens naturais desse ponto de vista - o que o autor denomina de Lógica Fregeana em Sentido Estrito - é um tipo de Lógica Livre.

Lógicas livres são, grosseiramente falando, linguagens artificiais que não respeitam $\mathbf{P 2}$ na medida em que nessas lógicas há termos sem referência, os denominados termos vazios. Lógicas livres positivas, por exemplo, são lógicas em que se um termo singular $\mathbf{t}$ não tiver referência, sentenças do tipo "t é P” podem ser verdadeiras. Já lógicas livres negativas são aquelas em que a ocorrência de um termo singular $\mathbf{t}$ sem referência força que sentenças do tipo “t é P" sejam falsas (NOLT, 2020). Daqui, podemos inferir que tanto a lógica livre positiva quanto a negativa respeitam $\mathbf{P 1}$ mas não respeitam P2, portanto, tampouco respeitam $\mathbf{P C}$.

guagem escrita à falada é sua invariância e permanência. Essas vantagens são mais bem exploradas, por exemplo, pela linguagem da aritmética. Para Frege, esse tipo de linguagem expres sa as coisas diretamente, sem precisar da medição sonora. Mas a linguagem aritmética não consegue expressar conexões lógicas. Daí a necessidade de uma Conceitografia, na acepção estrita to termo (2009, 63-65). 
A lógica de Frege, segundo Lehmann, não é uma lógica livre positiva nem negativa. É o que o autor denomina lógica NINO, abreviação inglesa para No Input, No Output (LEHMANN, 1994, p. 310) e que, mais tarde, passou a ser considerada um tipo de Lógica Livre Neutra (NOLT, 2020). Em NINO, PC é respeitado, de modo que se um termo sem referência ocorre numa sentença, a sentença como um todo não terá valor de verdade; porém, se todos os termos que ocorrem numa sentença tiverem referência, a sentença como um todo será ou verdadeira ou falsa. Como toda lógica livre, a lógica de Lehmann não respeita P2; e, por ser uma Lógica Livre Neutra, a lógica de Lehmann também não respeita $\mathbf{P 1}$.

Vimos que, para Frege, as linguagens naturais respeitam PC e, ao mesmo tempo, não respeitam P1 nem P2. Daqui, podemos inferir que a Lógica Livre Neutra de Lehmann é um modelo bastante fidedigno à filosofia da linguagem de Frege. Ou, se formos mais cautelosos, podemos assegurar que a lógica de Lehmann está muito mais próxima da filosofia da linguagem fregeana do que as demais alternativas vistas até então: lógica do tipo clássico, a lógica livre positiva e a lógica livre negativa.

Concluímos, portanto, que há ao menos dois sentidos de "lógica fregeana”. No primeiro sentido, é a linguagem artificial proposta por Frege. Essa lógica fregeana é claramente a Conceitografia, que respeita P1, P2 e PC. Num segundo sentido, podemos entender como "lógica fregeana" a linguagem artificial que pretende ser um modelo formal de sua concepção filosófica da linguagem. E é justamente nesse segundo sentido que a lógica fregeana é a Lógica Livre Neutra de Lehmann.

\section{Russell e as Descrições Definidas}

O problema da abordagem fregeana dos termos singulares é que ela nos leva ao seguinte paradoxo. Visto que Ulisses é um nome ficcional, então a sentença

(1) Ulisses não existe 
deveria ser verdadeira. Mas como, para Frege, "Ulisses" é um termo singular sem referência, temos, por PC, que a sentença (1) não pode ser nem verdadeira nem falsa. Aqui, estamos diante do seguinte paradoxo fregeano com relação aos nomes próprios ficcionais: se Fulano de Tal nunca existiu, então a sentença "Fulano de Tal não existe" não é verdadeira (mas também não é falsa).

A solução de Russell em Da Denotação é entender as condições de verdade da sentença (1) como condições verdade de um outro tipo de sentença, em que uma certa descrição definida substitui o nome próprio Ulisses em (1). Descrições definidas são expressões que começam com um artigo definido singular da forma: “o(a) $\mathbf{x}$ tal que ...” (1974b, p. 11).

Os artigos definidos singulares "o" e "a” são, na visão russelliana, abreviações de uma sentença complexa envolvendo quantificadores. ${ }^{7}$ A função lógica desses artigos definidos singulares é garantir a existência e unicidade. Assim, para Russell, a sentença (1) deve ser entendida como:

(1r) Não é o caso que existiu um único ${ }^{8} \mathbf{x}$ tal que $\mathbf{x}$ era rei de Ítaca, $\mathbf{x}$ lutou na Guerra de Troia...

Aqui, as reticências devem ser preenchidas por todas as demais características de Ulisses descritas por Homero na Ilíada e na Odisseia. ${ }^{9}$ Como Ilía-

\footnotetext{
${ }^{7}$ Isso quer dizer que contextos sentenciais em que ocorrem descrições definidas devem ser parafraseados em contextos em que essas descrições definidas não ocorrem. Para isso, usamos quantificadores, operadores lógicos e a igualdade.

${ }^{8} \mathrm{Na}$ linguagem formal de Russell, o quantificador "existe um único x" não é primitivo. Como símbolos primitivos temos: (i) o quantificador universal "para todo x"; (ii) o operador unário "não"; (iii) o operador binário "se... então"; e (iv) a relação binária "x é igual a y". Com o quantificador universal e a negação, podemos claramente definir o existencial. Por exemplo, a sentença "existe ao menos um $\mathbf{x}$ que tem a propriedade $\mathbf{P}$ " é equivalente, por definição, a "não é o caso que para todo $\mathbf{x}, \mathbf{x}$ não tem a propriedade $\mathbf{P}$ ". Em seguida, podemos expressar a sentença "existe um único $\mathbf{x}$ que tem a propriedade $\mathbf{P}$ " do seguinte modo: "existe ao menos um $\mathbf{x}$ que tem a propriedade $\mathbf{P}$ e, para todo $\mathbf{y}$, se $\mathbf{y}$ tem a propriedade $\mathbf{P}$, então $\mathbf{y}$ é igual a $\mathbf{x}$ ". A primeira parte da sentença garante que existe ao menos um $\mathbf{x}$, enquanto a segunda parte garante que não existe mais de um x (1974b, p. 10-11).

${ }^{9}$ Em A Filosofia do Atomismo Lógico, Russell usa como exemplo a sentença "Rômulo existiu", em que o nome Rômulo deve ser substituído por "existiu um único $\mathbf{x}$ tal que $\mathbf{x}$ tem tais e tais propriedades", tendo em vista todas aquelas propriedades que encontramos nos textos do historiador romano Títio Lívio (1974a, p. 111). Em Introdução à Filosofia Matemática, o mesmo método é usado para decidir o valor de verdade da sentença "Homero existiu": devese determinar se é verdadeira a sentença "existiu um único $\mathbf{x}$ tal que $\mathbf{x}$ escreveu a Ilíada e a Odisseia" (1996, p. 213).
} 
da e a Odisseia são obras ficcionais, sabemos que (1r) é verdadeira. Mas (1r) expressa as condições de verdade de (1). Desse modo, como (1r) é verdadeira, (1) também é verdadeira, como esperávamos. E isso, segundo Russell, eliminaria o paradoxo da abordagem de Frege dos termos singulares.

Para compreendermos melhor a teoria de Russell, vamos aplicá-la ao seguinte exemplo de Frege:

(2) Ulisses desembarcou em Ítaca.

Como vimos, para Frege a sentença (2) não é nem verdadeira nem falsa, pois "Ulisses" não tem referência. Para Russell, porém, a sentença (2) deve ser analisada do seguinte modo:

(2r) Existiu um único $\mathbf{x}$ tal que $\mathbf{x}$ era rei de Ítaca, $\mathbf{x}$ lutou na Guerra de Troia e ... e esse $\mathbf{x}$ desembarcou em Ítaca.

A sentença (2), para Russell, não deve ser considerada sem valor de verdade, como acreditava Frege, mas falsa. A razão para isso é a seguinte. Sabemos que a Ilíada e a Odisseia tratam-se de obras ficcionais e, portanto, nunca existiu um indivíduo que realizou todos os feitos que Homero atribui a Ulisses. Desse modo, a expressão "x era rei de Ítaca, $\mathbf{x}$ lutou na Guerra de Troia...” é falsa para qualquer valor de x. Daí, concluímos que a sentença (2r) é falsa. Mas (2r) expressa as condições de verdade de (2). Portanto, como (2r) é falsa, (2) também é falsa.

Tomemos agora a seguinte sentença:

(3) Ulisses não desembarcou em Ítaca

Para Frege, (3) também não é nem verdadeira nem falsa, desrespeitando P1. Mas para Russell (1974b, p. 17-18), tal sentença é ambígua. Desse modo, há duas maneiras de analisar as condições de verdade de (3), a saber: 
(3r) Existiu um único $\mathbf{x}$ tal que $\mathbf{x}$ era rei de Ítaca, $\mathbf{x}$ lutou na Guerra de Troia e ... e esse $\mathbf{x} \underline{\text { não }}$ desembarcou em Ítaca;

(3r*) Não existiu um único $\mathbf{x}$ tal que $\mathbf{x}$ era rei de Ítaca, $\mathbf{x}$ lutou na Guerra de Troia e ... e esse $\mathbf{x}$ desembarcou em Ítaca.

Visto que Ulisses nunca existiu, então (3r) é falsa e (3r*) é verdadeira. Uma das vantagens da abordagem de Russell é que ela respeita P1 mesmo para aquelas sentenças em que ocorrem nomes ficcionais. De fato, enquanto Frege entende que nomes ficcionais são termos singulares sem referência, Russell defende que sentenças em que ocorrem tais termos devem ser reescritas de modo a eliminar tais termos, obtendo, assim, sentenças logicamente equivalentes envolvendo existência e unicidade. Logo, toda sentença em que ocorrem termos singulares será ou verdadeira ou falsa, independentemente desses termos singulares terem ou não referência, que é o que exige P1.

Além disso, PC é respeitado na perspectiva russeliana pela seguinte razão. Sentenças em que ocorrem termos singulares são, em geral, reescritas de modo a obter sentenças logicamente equivalentes em que ocorre o operador existencial e a igualdade. A sentença reescrita, por sua vez, será verdadeira caso o termo singular tenha referência ou falsa caso o termo singular não tenha referência. Além disso, calcular o valor de verdade de uma sentença em que ocorre um termo singular é o mesmo que calcular o valor de verdade de uma sentença complexa cujo pedaço é uma descrição definida, ou seja, cujo pedaço também é uma sentença, mas de complexidade menor. Ora, se quisermos calcular o valor de verdade da sentença mais complexa, temos que calcular o valor de verdade de um pedaço menos complexo primeiro para, em seguida, calcular o valor de verdade da sentença como um todo, que é mais complexa. Assim, a verdade ou a falsidade dependem tanto da referência dos termos singulares que nela ocorrem quanto da verdade ou falsidade das sentenças componentes e do modo como estão combinadas, que é o que afirma PC. ${ }^{10}$

${ }^{10}$ A verdade e falsidade devem ser pensadas no vocabulário russeliano não como objetos lógicos, mas como um modo pelo qual certa proposição aponta para um fato correspondente 
A abordagem de Russell também respeita P2, mas de uma maneira indireta. Isso porque Russell entende que grande parte daquilo que foi denominado pela tradição de termos singulares é, na verdade, sentenças envolvendo existência e unicidade. Além de descrições definidas e termos ficcionais, outros termos devem ser entendido como sentenças. Esse é o caso, por exemplo, de nomes próprios como "Apolo", que pode ser entendido como uma abreviação da descrição definida “o deus Sol” (RUSSELL, 1974b, p. 18-19). Mesmo nomes próprios de seres humanos reais são, em sua maior parte, compreendidos como descrições definidas (RUSSELL, 1996, p. 213). O nome próprio "Aristóteles", por exemplo, poderia ser entendido por alguém como uma abreviação da descrição definida "o discípulo de Platão e preceptor de Alexandre Magno e..." em que as reticências abreviam certas propriedades que nós atribuímos a Aristóteles. ${ }^{11}$

Então quais expressões da linguagem natural seriam candidatas a legítimos termos singulares para Russell? Isso depende do modo como conhecemos o objeto (RUSSELL, 1974b, p. 20). Se nós tivermos um conhecimento de trato (acquaintance) do objeto, então usamos um termo singular genuíno para nos referimos a este objeto. Grosso modo, temos um conhecimento de trato de um objeto quando tal conhecimento não ocorre por meio de descrições definidas, mas por meio de um acesso direto ao objeto. Isso acontece, basicamente, em duas situações. No primeiro caso, quando usamos nosso nome próprio para nos referirmos a nós mesmo, como a sentença “Aristóteles é filósofo" dita pelo próprio Aristóteles (RUSSEL, 2001 p. 62). No segundo caso, quando nos referirmos a algo que está no nosso campo de percepção. No caso do português, a maneira mais comum de nos referirmos a algo que está próximo a nós é por meio dos pronomes "este", "esta" e "isto", como em "isto é branco" (RUSSELL, 1974a, p. 77).

Quando falamos de nós mesmo, temos a garantia que nosso nome se refere a um único indivíduo e que, portanto, tem uma única referência. É o (RUSSELL, 1974a, p. 84). De qualquer modo, a expressão "valor semântico" abarca o verdadeiro e o falso não só como objetos lógicos, mas também como correspondência entre proposições e fatos. Agradecemos ao parecerista deste artigo pela perspicaz observação.

${ }^{11}$ De acordo com Russell, a propriedades atribuídas na descrição definida que substitui o nome próprio "Aristóteles" dependem do grau de intimidade que a pessoa que usa o nome "Aristóteles" tem com Aristóteles (Russell, 2001, p. 63) 
conhecimento de trato de nossa autoconsciência que garante referência ao nosso nome próprio nessa situação (RUSSELL, 2001, p. 58). Além disso, quando estamos diante de algo do nosso campo de percepção, estamos diante de um particular. Nesse caso, ao usarmos os pronomes "este", "esta" e "isto", temos também a garantia de estamos nos referindo a um único objeto existente (RUSSELL, 1974a, p. 78). Podemos concluir daqui que o conhecimento de trato dos termos singulares genuínos garantem que a filosofia da linguagem de Russell também respeite $\mathbf{P 2}$.

\subsection{Há Uma Lógica da Filosofia da Linguagem em Russell?}

Enquanto em Frege há uma distinção nítida entre a lógica apresentada em sua Conceitografia e a lógica de sua concepção filosófica da linguagem, a linha divisória se torna muito mais tênue no caso de Russell. Há, acredito, duas razões para isso.

A primeira razão de Russell não separar lógica de filosofia da linguagem natural é a seguinte. Tanto Frege quanto Russell viam numa lógica do tipo clássico a melhor maneira de reformular a matemática de modo a abandonar as imprecisões e ambiguidade que ocorrem quando os enunciados matemáticos são apresentados em linguagem natural. Mas sabemos que a linguagem matemática permite falar de termos singulares que não se referem a nada, por exemplo, o termo singular “a divisão de 1 por 0" não se refere a número algum. De acordo com o próprio Russell, a solução dada por ele anteriormente a esse problema havia sido a mesma defendida por Frege: atribuir uma referência arbitrária a todos esses termos matemáticos que não se referem a nada.

Mas no momento em que escreve Da Denotação, Russell admite que a solução de Frege não o satisfaz e apresenta essa como sendo uma das razões para adotar sua teoria das descrições definidas para lidar com o problema de termos singulares sem referência na linguagem natural (1974b, p. 10). Ou seja, sua nova solução para os termos singulares vazios na linguagem formal da lógica matemática é automaticamente aplicada à linguagem natural, sem qualquer mediação. Esse é um bom motivo para admitirmos que, para Russell, 
não havia distinção alguma entre a linguagem formal adequada para o contexto matemático e a linguagem formal como mecanismo de análise de expressões linguísticas no seu uso cotidiano.

Além disso, cabe lembrar que um dos motivos de Russell preferir sua abordagem em detrimento à abordagem de Frege dos termos singulares na linguagem natural é porque ela preserva o Princípio do Terceiro Excluído (law of excluded middle), que é o princípio pressuposto em P1 ${ }^{12}$ Mas esse princípio não é necessariamente um princípio da linguagem natural em seu uso cotidiano, e sim um princípio de uma lógica de tipo clássico. Russell está aqui, mais uma vez, defendendo que uma lógica do tipo clássico é o mecanismo mais adequado para análise da linguagem natural nos seus mais diversos usos.

Entendo, desse modo, que há sim uma lógica da filosofia da linguagem de Russell, mas que essa lógica é a própria versão russeliana da Lógica Clássica.

\section{Strawson Contra Russell}

A teoria das descrições definidas de Russell parecia ter dado uma resposta definitiva ao problema dos termos singulares sem referência e, durante cerca de cinquenta anos, se tornou praticamente consensual entre os filósofos analíticos. A polêmica foi reacendida por Strawson em seu artigo Sobre o Referir.

Para Strawson, o problema da teoria das descrições de Russell é que ela não está de acordo com o uso corrente da linguagem. Para defender esse ponto de vista, Strawson considera o seguinte exemplo:

(5) O atual rei da França é sábio.

\footnotetext{
${ }^{12}$ Em (RUSSELL, 1974a) traduz-se a expressão original law of excluded middle (RUSSELL, 1905, p. 485) por "lei da exclusão dos meios". Embora literal, essa tradução não está de acordo com a expressão normalmente usada em manuais de lógica em língua portuguesa. Vide (MORTARI, 2016, p. 247) e (HEGENBERG, p. 57).
} 
Na visão de Russell, a descrição definida "o atual rei da França” deve ser entendida como "existe um único $\mathbf{x}$ tal que $\mathbf{x}$ é rei da França”. Desse modo, a sentença (5) deve ser equivalente em significado a:

(5r) Existe um único $\mathbf{x}$ tal que $\mathbf{x}$ é rei da França e $\mathbf{x}$ é sábio.

Tendo em vista que uma parte da sentença expressa em (5r), a saber, "x é rei da França" é falsa para todo $\mathbf{x}$, temos que a sentença (5r) como um todo também é falsa. Mas se perguntarmos a alguém na rua se é verdade que o rei da França é sábio, a pessoa provavelmente ficará muito encabulada e não saberá responder. Como enfatiza Strawson, em vez de dizer que (5) é simplesmente falsa, a pessoa pedirá para você repetir a pergunta ou dirá algo do tipo "você cometeu um equívoco, não há mais rei na França”. Por outro lado, se (5) fosse proferida (uttered) em vários momentos durante o século XVIII, ela poderia ser verdadeira ou falsa, dependendo a que monarca o falante estivesse se referindo (STRAWSON, 1974, p. 270-271).

Daqui, Strawson defende que devemos distinguir entre a utilização de uma expressão e o proferimento de uma expressão. Se duas pessoas usarem a expressão "o atual rei da França" em tempos diferentes, elas podem estar se referindo $^{13}$ (referring) a monarcas distintos. Nesse caso, são duas utilizações distintas da mesma expressão. Se essas duas pessoas estiverem pronunciando a expressão ao mesmo tempo, estamos diante da mesma utilização dessa expressão, mas em dois proferimentos distintos.

Porém, quando (5) é proferida em 1950, a expressão "o atual rei da França" não se refere a nada e (5), portanto, não é nem verdadeira nem falsa, pois a questão da verdade ou falsidade de (5) sequer pode ser colocada. Strawson ainda defende na mesma obra que nomes próprios ficcionais também não

\footnotetext{
${ }^{13}$ Russell em Da Denotação espelha a distinção fregeana entre Sinn e Bedeutung como meaning e denotation (1905, p. 483). Já Strawson usa significance como sinônimo de meaning e referring como sinônimo de denotation (1950, p. 323). Para aproximar o diálogo entre esses autores, estamos aqui traduzindo meaning e significance por "significado" enquanto os três termos Bedeutung, denotation e referring traduzimos indiscriminadamente por "denotação" ou "referência". Sabemos, porém, que os conceitos de denotation e referring não são coextensivos em inglês. Conferir o artigo de Donellan intitulado Reference and Definite Description (1966, p. 281-282).
} 
têm referência. Desse modo, ele concorda com Frege que a sentença (2) não tem valor de verdade, visto que "Ulisses" não tem referência.

À primeira vista, a solução de Strawson não parece resolver sentenças do tipo (1). Mas no final de seu artigo, Strawson insiste que em proposições do tipo “Algum homem é mortal” está pressuposta a existência de seres humanos para ela ser verdadeira ou falsa. Se aplicarmos o mesmo raciocínio de Strawson não apenas para termos gerais mas também para termos singulares, diríamos que a existência de Ulisses está pressuposta para (1) ser verdadeira ou falsa e que, portanto, a questão da verdade ou falsidade de (1) sequer deve ser levantada em contextos ficcionais.

Outra maneira de contornar a dificuldade é dizer que (1) não expressa uma proposição justamente porque é usada em um contexto ficcional. Como defende Caorsi em seu texto Referência e Termos Singulares, Strawson parece oscilar entre essas duas posições não apenas nesse artigo mas também em outras obras posteriores (CAORSI, 2005, p. 179-181). Strawson replica Caorsi, enfatizando que, na verdade, essas duas posições não são mutualmente incompatíveis e mostra como reconciliá-las (STRAWSON, 2014, p. 83).

\subsection{As Lógicas da Filosofia da Linguagem de Strawson}

É verdade que Strawson nunca apresentou uma lógica formal para sua filosofia da linguagem. De fato, Strawson admite, em sua réplica a Caorsi, que o problema da lógica subjacente à sua filosofia da linguagem nunca o atraiu (2014, p. 84). Além disso, o seu texto Sobre o Referir finaliza concluindo que "nem as regras aristotélicas nem as russellianas fornecem a lógica exata de qualquer expressão da linguagem ordinária, pois a linguagem ordinária não tem uma lógica exata" (1974, p. 286).

Em Russell, o problema da lógica exata subjacente a sua filosofia da linguagem sequer é colocado, em virtude de haver uma identidade entre sua lógica e sua filosofia da linguagem. Já tal problema pode sim ser colocado concernente à filosofia da linguagem de Strawson por, ao menos, dois motivos. Primeiramente porque, como vimos, o próprio Strawson admite que há uma separação entre lógica formal e lógica da linguagem natural. O segundo moti- 
vo é que existe, na literatura, ao menos duas tentativas de abarcar a filosofia da linguagem de Strawson em termos formais. E essas duas tentativas usam lógicas que não respeitam P1 e P2, verificados em qualquer lógica do tipo clássico.

A primeira proposta, esboçada por Caorsi, é pensar uma lógica proposicional em que há um operador binário de pressuposição distinto da implicação material. ${ }^{14}$ Caorsi propõe a operação "p pressupõe q" de modo que "p pressupõe q" é verdadeiro quando a verdade de q é uma condição para a verdade ou falsidade de p (CAORSI, 2015, p. 180-181).

Caorsi, porém, não diz se esse operador binário de pressuposição deve ser definido numa lógica do tipo clássico ou não. Desse modo, cabe perguntar: Strawson está defendendo que é possível definir, além da implicação material, uma implicação de pressuposição numa lógica proposicional de tipo clássico? Esse não parece ser o caso. A alternativa - que parece ter sido indicada pelo próprio Strawson em sua réplica a Caorsi - é tomar uma lógica proposicional de três valores, em que o terceiro valor representaria o indeterminado (2014, p. 84). Uma lógica assim claramente não respeitaria $\mathbf{P 1}$.

Existem, na literatura, várias lógicas proposicionais de três, quatro e até infinitos valores de verdade. Em cada uma dessas lógicas, podemos definir mais de uma implicação. Mas não vejo como definir a operação “p pressupõe q" em qualquer uma dessas lógicas e a razão é a seguinte. Segundo a perspectiva de Caorsi endossada por Strawson, se (5) receber o valor indeterminado é porque (5r) é falso. Isso significa que o valor de verdade de (5r) depende do valor de verdade de (5) para que “(5) pressupõe (5r)" seja verdadeiro. Daqui, se segue que a relação "p pressupõe q" não é uma função proposicional. ${ }^{15}$ Desse modo, a relação “p pressupõe q" não pode ser definida em qualquer ló-

\footnotetext{
${ }^{14}$ A implicação material é uma implicação definível em qualquer lógica proposicional do ti po clássico. As condições de verdade de uma implicação material são: dadas duas proposições $\mathbf{p}$ e $\mathbf{q}$, temos que "p implica $\mathbf{q}$ " é falso apenas no caso em que $\mathbf{p}$ é verdadeiro e $\mathbf{q}$ é falso; nos demais casos, "p implica q" é verdadeiro.

15 Talvez esse ponto fique mais claro com uma analogia. A relação "a soma de $\mathbf{x}$ com $\mathbf{y}$ " é uma operação numérica da aritmética porque a função tem apenas os valores de $\mathbf{x}$ e de $\mathbf{y}$ como entrada, de modo que tanto $\mathbf{x}$ como $\mathbf{y}$ se referem a números. Já a relação "p pressupõe $\mathbf{q}$ " não pode ser uma operação proposicional. De fato, quando "p pressupõe q" é verdadeiro, tanto p quanto q são sentenças envolvendo quantificadores.
} 
gica proposicional, independentemente de quantos valores de verdade essa lógica viesse a ter.

Buscando mudar a lógica no que diz respeito não à implicação mas à referência dos termos singulares, van Frassen considerou uma lógica livre neutra diferente da de Lehmann como a lógica da filosofia da linguagem de Strawson com relação ao tratamento dos termos singulares (1966, p. 181). A ideia fundamental de van Fraasen é que sentenças em que ocorrem expressões sem referência não têm valor de verdade, mas seria possível atribuir certas referências a essas expressões expandido o domínio de objetos.

A sugestão de van Fraasen foi desenvolvida tecnicamente alguns anos mais tarde por Bencivenga. Vamos denominar de domínio original de objetos aquele domínio em que, numa certa linguagem, há termos sem referência. Há muitas maneiras de expandir esse domínio original, atribuindo referências distintas aos termos que, outrora, não tinham referência. Uma sentença é verdadeira quando para toda expansão do domínio original a sentença é verdadeira, e uma sentença é falsa quando para toda expansão do domínio original a sentença é falsa. Quando a sentença é verdadeira para algumas expansões do domínio original e falsa para outras expansões, a sentença considerando o domínio original não é nem verdadeira nem falsa (BENCIVENGA, 1986, 9. 409). A lógica de Bencivenga, sendo uma lógica livre, claramente não respeita P2. E sendo uma lógica livre neutra, também não respeita $\mathbf{P 1}$.

A meu ver, essa solução se desvia um pouco da visão strawsoniana. De acordo com Strawson, a sentença (5) pode ser: (i) verdadeira se dita durante o reinado de Luís XIV; (ii) falsa se dita durante o reinado de Luís XV; (iii) sem valor de verdade se dita em 1950. Estamos aqui diante de três épocas distintas. Digamos que cada expansão do domínio original seja a contraparte formal daquilo que Strawson denomina época (time). Assim, a referência do termo singular "o atual rei da França” mudaria de época para época. A contrapartida desse fenômeno na linguagem formal de Bencivenga seria a seguinte: a referência de um termo singular $\mathbf{t}$ mudaria em cada expansão do domínio original (se expansões distintas do domínio original não forem a contraparte formal na lógica de Bencivenga para épocas distintas, não sei o que seria). 
Mas isso implica que na lógica de Bencivenga a sentença (5) seria sempre ou verdadeira ou falsa em cada expansão específica do domínio. E se a expansão do domínio é a contraparte formal de uma determinada época, teríamos que (5) seria sempre verdadeira ou falsa em cada época específica, apesar de não conseguirmos determinar a verdade ou a falsidade de (5) independentemente da época. Mas não é isso que diz Strawson: há épocas em que (5) não é nem verdadeira nem falsa, a saber, na época em que o termo "o atual rei da França" não se refere a ninguém. Os modelos de Bencivenga, porém, diriam outra coisa: a sentença (5) não é "eternamente" nem verdadeira nem falsa porque em certas épocas (5) é verdadeira e em outras épocas (5) é falsa, mas não haveria uma época em que (5) não fosse nem verdadeira nem falsa.

Isso nos sugere considerar a lógica NINO de Lehmann mais próxima da filosofia da linguagem de Strawson do que a de Bencivenga se não fosse pela seguinte limitação. Em NINO, não há nada que possa interpretar o termo “atual" na própria linguagem formal e, portanto, fica difícil considerar NINO um modelo apropriado daquilo que seria a época de enunciação de (5) para Strawson.

Aqui, a palavra-chave parece ser "atual", que pertence a uma certa categoria de palavras que Kaplan denominou indexicais. Além disso, como veremos adiante, a filosofia da linguagem de Kaplan parece ter uma contraparte formal muito adequada nas denominadas lógicas híbridas. Mas para compreendermos, em linhas gerais, a filosofia da linguagem de Kaplan e os modelos de lógica híbrida, é preciso retrocedermos um pouco e compreendermos alguns conceitos básicos da filosofia da linguagem de Kripke e a sua lógica modal.

\section{Kripke e os Designadores}

Para Frege, nomes próprios são termos singulares que têm mais de um sentido (Sinn). Esse sentido normalmente é expresso por meio de uma descrição definida. Por exemplo, um dos sentidos do nome próprio "Vênus" é "a estrela da manhã", outro sentido do mesmo nome próprio é "a estrela da tarde". 
Ambos os sentidos se referem ao mesmo objeto, que é um certo corpo celeste no nosso sistema solar.

Russell, por sua vez, discorda que nomes próprios sejam termos singulares cujo sentido é uma certa descrição definida, podendo ou não se referir a um certo objeto. Para ele, nomes próprios têm, em geral, a mesma função que descrições definidas. Do ponto de vista lógico, sentenças envolvendo descrições definidas devem ser reescritas de modo a obter uma sentença equivalente envolvendo existência e unicidade. Se há uma única denotação para o nome próprio, a sentença é verdadeira; caso contrário, ela é falsa.

Mas há algo comum nessas duas perspectivas. Em ambas, há uma relação muito estrita entre nomes próprios da linguagem natural e descrições definidas. Em Frege, a descrição definida determina o sentido de um nome próprio; em Russell, a descrição definida determina o valor de verdade de uma sentença em que ocorre um nome próprio.

Kripke, em O Nomear e a Necessidade, se contraporá àquilo que ele denomina de perspectiva de Frege e Russell sobre os termos singulares, ou seja, "designadores" no vocabulário kripkeano (2012, p. 70). ${ }^{16}$ Grosseiramente, essa perspectiva pode ser resumida segundo Kripke do seguinte modo: para Frege, descrições definidas são cruciais para determinar o sentido/significado de um nome; para Russell, elas são fundamentais para determinar a denotação/referência de um nome. Kripke defende que descrições definidas não têm nenhum papel para determinar quer o significado quer o referente do nome. Além disso, Kripke dirá que um nome próprio sequer têm sentido/significado, mas se refere sempre diretamente ao objeto portador do nome.

Para defender sua tese, Kripke usa argumentos modais, ou seja, análises de sentenças da linguagem natural em que ocorrem termos modais como “necessário", “contingente” e "possível”. Vejamos um exemplo do próprio Kripke (2012, p. 110):

\footnotetext{
${ }^{16}$ Para sermos fiéis ao trecho citado, o conceito de "designador" engloba apenas nomes próprios e descrições definidas, mas não engloba expressões como "este homem", em que há um pronome seguido de um termo geral. Porém, cabe mencionar que, em outra passagem, Kripke sugere que pronomes também devam ser compreendidos como designadores (2012, p. $51)$.
} 
(6) Aristóteles poderia não ter sido discípulo de Platão.

Sabemos que (6) é verdadeira. Mas se o nome próprio "Aristóteles" for sinônimo da descrição definida "o discípulo de Platão e mestre de Alexandre Magno", então (6) seria contraditória, pois seria equivalente à sentença "o discípulo e Platão e mestre de Alexandre poderia não ter sido discípulo de Platão".

Pela nossa intuição, (6) não é contraditória; e sim, verdadeira. Desse modo, o nome próprio "Aristóteles" não deve ser entendido com sinônimo da descrição definida "o discípulo de Platão e mestre de Alexandre Magno". O argumento modal pode ser facilmente generalizado para qualquer descrição definida atribuída ao nome "Aristóteles", por maior que ela fosse. Fica clara, assim, a limitação da teoria das descrições definidas dos nomes próprios como teoria que busca determinar o sentido/significado dos nomes próprios.

Esse argumento pode ser facilmente adaptado para o problema de determinar o valor de verdade da sentença (6). Pela nossa intuição, (6) é verdadeira. Vimos, porém, que pela teoria das descrições definidas, a sentença (6) é contraditória, ou seja, verdadeira e falsa ao mesmo tempo. Considerando que o valor de verdade é a referência de uma dada sentença, temos que o argumento modal mostra também um problema na teoria das descrições definidas dos nomes próprios como teoria que determina a referência/denotação dos nomes próprios.

Kripke enfatiza que, para determinar o valor de verdade de (6), temos que pensar numa situação contrafactual. Nessa situação contrafactual, que ele denomina de um outro mundo possível, Aristóteles teria tido qualquer outra ocupação diferente de fazer filosofia. Nesse mundo possível, usamos o nome próprio "Aristóteles" para nos referirmos ao mesmo indivíduo Aristóteles. Já a descrição definida "o discípulo de Platão e mestre de Alexandre Magno" poderia se referir nesse mundo, por exemplo, a Espeusipo (que também foi discípulo de Platão no mundo atual mas que não foi mestre de Alexandre o Grande no mundo atual) ou simplesmente a ninguém. 
Para se contrapor à perspectiva descritivista, Kripke defende duas principais teses. A primeira tese é a de que nomes próprios são designadores rígidos porque se referem ao mesmo indivíduo ao longo dos mundos possíveis. Já descrições definidas são designadores não-rígidos porque podem se referir a indivíduos distintos ao longo dos mundos possíveis (2012, p. 98-99).

A segunda tese é a de que, na maioria dos casos, a referência dos nomes próprios não é fixada por meio de descrições definidas, mas sim a partir de um batismo inicial. ${ }^{17}$ Em seguida, o nome espalha-se de elo em elo numa cadeia comunicativa dentro de comunidade de falantes.

\subsection{As Lógicas Modais de Kripke}

Nota-se que todas as objeções de Kripke à teoria descritivista estão alicerçadas sobre uma maneira de interpretar as expressões modais "necessário" e "possível". Em termos mais técnicos, todas as objeções pressupõem uma semântica formal que interprete os operadores modais "necessário" e "possível".

Como devemos fazer para determinar o valor de verdade de uma sentença com um operador modal, como a sentença (6)? A solução que Kripke encontrou foi acrescentar aos modelos da Lógica de Primeira Ordem um conjunto de mundos possíveis. Na semântica relacional de Kripke, a sentença “necessário p" é verdadeira num mundo w quando p é verdadeira em todo mundo w' acessível a w. Já a sentença “possível p" é verdadeira num mundo $\mathbf{w}$ quando $\mathbf{p}$ é verdadeira em algum mundo w' acessível a w.

Assim, (6) será verdadeira se houver ao menos um mundo possível no modelo em que a sentença "Aristóteles foi discípulo de Platão" for falsa. Se em todos os mundos do modelo a sentença "Aristóteles foi discípulo de Platão" for verdadeira, teremos nesse modelo que (6) será falsa, pois não seria possível nesse modelo que Aristóteles não fosse discípulo de Platão.

Se entendermos as constantes individuais como contrapartida formal aos nomes próprios, torna-se evidente a relação estreita entre a Lógica Modal

\footnotetext{
${ }^{17}$ Isso não ocorre, porém, em todos os casos. Kripke chama atenção para o caso de Netuno, cujo nome próprio não foi dado por meio de um batismo inicial, mas como abreviação da descrição definida "o planeta a perturbar a órbita de Urano" (2012, p. 137).
} 
de Primeira Ordem e a tese de que nomes próprios são designadores rígidos. A função de atribuição de um modelo atribui a uma constante individual sempre o mesmo objeto do domínio, independentemente do mundo possível. Assim, as constantes individuais são claramente designadores rígidos nesse sistema. O passo seguinte foi defender, tendo esses modelos em mente, que os nomes próprios na linguagem natural são as constantes individuais da linguagem formal.

Já uma descrição definida do tipo "o discípulo de Platão e mestre de Alexandre Magno" entendida à la Russell como "existe um único $\mathbf{x}$ tal que $\mathbf{x}$ foi discípulo de Platão e mestre de Alexandre Magno" pode ser verdadeira ou falsa, dependendo do mundo possível em que ela for interpretada. Num mundo possível em que ela fosse falsa, a descrição definida "o discípulo de Platão e mestre de Alexandre Magno" não se referiria a ninguém. Num mundo possível em que ela fosse verdadeira, a função de atribuição poderia atribuir a $\mathbf{x}$, por exemplo, o indivíduo Espeusipo. Nesse mundo possível, a descrição "o discípulo de Platão e mestre de Alexandre Magno" se referiria a Espeusipo. Nesse sentido, descrições definidas não são rígidas, pois sua referência varia de mundo para mundo.

A tese de que as constantes individuais em sistemas modais devem ser entendidas como nomes próprios da linguagem natural foi claramente o que inspirou a filosofia da linguagem de Kripke. ${ }^{18}$ Também não é difícil acomodar essa tese com a visão russeliana de que as descrições definidas da linguagem natural devem ser compreendidas como sentenças envolvendo existência e unicidade. Desse modo, está clara a relação intrínseca entre a filosofia da linguagem de Kripke e a Lógica Modal de Primeira Ordem. ${ }^{19}$

\footnotetext{
18 Isso é admitido pelo próprio Kripke (2012, p. 34-44).

${ }^{19}$ No artigo A Completeness Theorem in Modal Logic, a Lógica Modal de Primeira Ordem tratada por Kripke é uma extensão de primeira ordem do sistema modal S5 de Lewis e Langford. Seria temerário, porém, afirmarmos que a lógica da filosofia da linguagem de Kripke é apenas a extensão de primeira ordem de $\mathbf{S 5}$ por algumas razões. Em seu artigo posterior Semantical Analysis of Modal Logic I, Kripke acrescenta aos modelos proposicionais de S5 uma relação de acessibilidade entre os mundos possíveis (1963, p. 68), obtendo o resultado de completude para o sistema S4 de Lewis e Langford (1963, p. 82). Em Semantical Analysis of Modal Logic II, Kripke enriquece ainda mais seus modelos, dividindo o conjunto de mundos possíveis em normais e não-normais (1966, p. 210) tendo como resultado a completude dos sistemas S2 e S3 de Lewis e Langford (1966, p. 214-217). Não há nenhuma razão para acreditar que Kripke considerava mais legítima do ponto de vista filosófico a extensão de primeira ordem de $\mathbf{S 5}$ em detrimento às extensões de primeira ordem de $\mathbf{S 4}, \mathbf{S 3}$ ou
} 
Mais do que isso, somos forçados a admitir que a filosofia da linguagem de Kripke é fruto de sua semântica formal de mundos possíveis. Essas considerações nos obrigam a colocar Kripke, juntamente a Russell, no grupo de lógicos que entendem a linguagem humana como uma maquinaria complexa, e que cabe ao filósofo desvendar o seu funcionamento. Também está mais do que claro que, para Kripke, não há, como em Frege, duas lógicas. O que há é uma única lógica, que é a lógica da sua filosofia da linguagem.

Por fim, a Lógica Modal de Primeira Ordem de Kripke claramente respeita o princípio PC num sentido mais fraco: o valor de verdade de uma sentença complexa envolvendo modalidades como (6) é determinada pelo valor de verdade da sentença subordinada menos complexa no nosso mundo e em outros mundos possíveis. Nesse sistema, vale claramente tanto P1 quanto P2. Mas P2 vale apenas num sentido mais fraco: todos os designadores rígidos se referem a um único indivíduo existente no nosso mundo atual, mas que poderia não existir em outros mundos possíveis. ${ }^{20}$ Tendo essas ponderações em mente, podemos inferir que a Lógica Modal de Primeira Ordem é uma lógica do tipo clássico. Foi apenas para fins esquemáticos que, na introdução desse artigo, denominamos a lógica de Kripke de simplesmente Lógica Modal Clássica, por mais vaga e simplista que seja essa denominação.

S2. De fato, Kripke não parece se comprometer filosoficamente com nenhum tipo de acessibilidade entre os mundos possíveis.

${ }^{20}$ Está claro em $O$ Nomear e a Necessidade que os objetos referidos pelos designadores rígidos não são necessariamente existentes. Isso porque Kripke denominava de designador fortemente rígido aqueles nomes próprios e descrições definidas que se referem a um único indivíduo necessariamente existente, ou seja, existente em todos os mundos possíveis, não apenas no nosso mundo atual. Esse seria o caso, por exemplo, do numeral "1" e da descrição definida "o sucessor de 0 ": ambos os termos se referem a um único indivíduo, o número 1 , que existe em todos os mundos possíveis (KRIPKE, 2012, p. 99). Porém, no mesmo texto não está tão claro que um designador rígido deva necessariamente se referir a um indivíduo existente no nosso mundo atual ou, ao menos, em algum mundo possível. Kripke diz simplesmente que "uma expressão é um designador rígido se ela designar o mesmo objeto em todos os mundos possíveis" (KRIPKE, 2012, p. 99). Em sua introdução para a tradução portuguesa, Santos defende que "a questão de saber se um nome continua a designar o mesmo objeto nos mundos possíveis em que esse objeto não existe é controversa" e emenda que o próprio Kripke parece oscilar em outras obras a respeito dessa questão (KRIPKE, 2012, p. 23). 


\section{Kaplan e os Indexicais}

Russell respondeu às objeções de Strawson a sua teoria das descrições definidas de maneira leviana e impaciente. Para ele, Strawson se ateve demais à palavra "atual". Segundo Russell, esse é um tipo de palavra "egocêntrica". Palavras egocêntricas podem se referir a objetos distintos em situações diferentes e, portanto, são intrinsecamente ambíguas. Mas a ambiguidade pode ser facilmente eliminada se substituirmos a sentença (5) pela proposição

(5p) O rei da França no ano de 1905 é sábio

que substitui, em (5), o termo "atual" pelo ano em que o artigo $D a$ Denotação foi publicado (RUSSELL, 1957, p. 385). ${ }^{21}$

Aqui, fica clara a técnica de Russell: as chamadas palavras egocêntricas devem ser eliminadas, de modo que toda sentença em que elas ocorrem deve ser substituída, na análise lógica, por uma sentença equivalente em significado que elimine essas palavras. Isso ocorre não apenas com "atual”, mas também com palavras como "eu", "aqui", "agora", etc.

Enquanto Russell classifica essas palavras como "egocêntricas", Kaplan em seu artigo Demonstratives: An Essay on the Semantics, Logic, Metaphysics, and Epistemology of Demonstratives and Other Indexicals as denomina de indexicais. De acordo com Kaplan, indexicais englobam: pronomes como "eu”, "meu”, “ele”, "seu”, “ela”, "sua”; pronomes demonstrativos como "esse", "aquele"; advérbios como "aqui”, "agora”, “ontem”, "amanhã"; adjetivos como "atual", "presente", dentre outros (1989, p. 489).

Para Kaplan, os indexicais devem ser divididos em dois grupos. O primeiro grupo é formado por indexicais em que o referente é fixado por meio de uma apresentação, normalmente visual, do objeto, ao apontarmos para ele. Esse é o caso dos indexicais "este" e "aquele". Tais indexicais são chamados

\footnotetext{
${ }^{21}$ Outro ponto enfatizado por Russell em sua resposta a Strawson: enquanto Strawson está propondo fazer filosofia com a linguagem cotidiana, Russell está defendendo que uma linguagem formal, científica é necessária para fazer filosofia do mesmo modo que é necessário em outros campos, como na física e na química (1957, p. 387). Esse é mais um argumento a favor da tese defendida na Seção 2.1 deste artigo: para Russell, não há distinção entre lógica e filosofia da linguagem.
} 
de demonstrativos. Já indexicais como "eu", "agora" e "amanhã" são indexicais puros, pois não necessitam de um ato de demonstração para fixar o referente. Aqui, é o contexto que determina a referência (KAPLAN, 1989, p. 491-492)

Do ponto de vista semântico, Kaplan não propõe uma visão alternativa a de Kripke, e sim complementar. Vimos que, na semântica kripkeana, a função que determina o valor de verdade depende de uma proposição e de um mundo possível. Visando um comprometimento metafísico menor, Kaplan denomina os mundos possíveis de Kripke de "circunstâncias possíveis de valoração" (1989, p. 507).

Mas Kaplan faz uma complementação à teoria de modalidade de Kripke que não é simplesmente apresentá-la sobre uma nova roupagem. Além da função de verdade que associa a cada proposição em cada mundo um certo valor de verdade, há uma outra função para Kaplan. Essa outra função associa a cada sentença num certo contexto uma determinada proposição. Para compreendermos essa distinção, tomemos o seguinte exemplo:

(8) Eu poderia não ter sido discípulo de Platão

Imaginemos um contexto em que a sentença (8) seja dita por Aristóteles. Aqui, está claro que o significado de (8) nesse contexto é a mesma proposição expressa por (6), a saber, que Aristóteles poderia não ter sido discípulo de Platão. Dado esse conteúdo proposicional fixado pelo contexto, podemos decidir se há um mundo possível em que Aristóteles não é discípulo de Platão para, aí sim, determinar o valor de verdade da sentença (8) no contexto em que Aristóteles a pronuncia.

Agora, consideremos um outro contexto em que a mesma sentença (8) foi pronunciada por Espeusipo em vez de pronunciada por Aristóteles. Aqui, temos que considerar as circunstâncias possíveis de valoração de outra proposição, a de que Espeusipo poderia não ter sido discípulo de Platão.

O que concluímos daqui é que, para determinar se a sentença (8) é verdadeira ou falsa, é preciso, primeiramente, determinar que proposição é 
expressa por (8) num certo contexto. Em seguida, deve-se levar em conta as circunstâncias possíveis de valoração - os mundos possíveis - para, aí sim, determinarmos o valor de verdade de (8).

Vimos que as circunstâncias possíveis de valoração são, no vocabulário kaplaniano, os mundos possíveis de Kripke. Mas os contextos, por sua vez, determinam o que Kaplan denomina de conteúdo de uma sentença, que é o que normalmente chamamos de proposição. De acordo com Kaplan, quando Strawson (STRAWSON, 1950, p. 326) diz que usamos a sentença (5) para fazer asserções (statements) distintas, ele está afirmando, em outras palavras, que há conteúdos proposicionais distintos da mesma sentença em contextos distintos (1989, p. 501). ${ }^{22}$

Cabe ressaltar que a noção de conteúdo não cabe apenas a uma sentença, mas também às partes de uma sentença (KAPLAN, 1989, p. 501). Desse modo, o que faz a sentença (5) ser verdadeira ou falsa se enunciada em momentos distintos é a referência do indexical "atual". No contexto do reinado de Luís XIV, o termo singular "o atual rei da França” se refere ao indivíduo Luís XIV, de modo que poderíamos aceitar o conteúdo de (5) como verdadeiro. Já no contexto do reinado de Luís XV, o mesmo termo singular "o atual rei da França" se refere ao indivíduo Luís XV, de modo que poderíamos tomar o conteúdo de (5) com sendo falso.

\subsection{A "lógica" de Kaplan}

Kaplan defende que o significado (meaning) tem duas dimensões: um caráter e um conteúdo. O caráter é uma função de contextos para conteúdos. O conteúdo é uma função de circunstâncias possíveis para extensões. Em seguida, Kaplan diz explicitamente que ambas as funções respeitam PC (KAPLAN, 1989, p. 505-507)

\footnotetext{
${ }^{22}$ Kaplan (1989, p. 501) também chama de conteúdo de uma proposição aquilo que Frege (FREGE, 2009, p. 239) denominava de sentido de uma proposição, que é o pensamento. O autor, porém, pondera que o conceito fregeano de sentido de uma sentença confunde a noção epistemológica de diferença de cognição (por que sentenças do tipo $\mathbf{t}=\mathbf{t}$ difere em conteúdo cognitivo de sentenças do tipo $\mathbf{t}=\mathbf{t}^{\prime}$, em que $\mathbf{t}$ e $\mathbf{t}$ ' são termos singulares) com a noção semântica de conteúdo de uma sentença. Com relação ao papel dos indexicais para determi nar o sentido de uma sentença, diz Frege: “o mesmo enunciado que encerre a palavra 'eu' ex pressará, quando proferido por diferentes pessoas, diferentes pensamentos, alguns dos quais poderão ser verdadeiros, e outros, falsos" (FREGE, 2002, p. 20).
} 
A semântica formal de Kaplan consistia, a princípio, em enriquecer os modelos kripkeanos de modo que um contexto fosse determinado por uma quádrupla (w, $\mathbf{x}, \mathbf{p}, \mathbf{t})$ em que $\mathbf{w}$ é um mundo possível, $\mathbf{x}$ é um agente, $\mathbf{p}$ é um ponto no espaço e $\mathbf{t}$ é um instante no tempo. Mas tal enriquecimento não é o suficiente para manter distinções intuitivas em sentenças envolvendo indexicais. Tomemos o seguinte exemplo de Kaplan:

(9) Eu estou aqui agora.

Dado um certo contexto ( $\mathbf{w}, \mathbf{x}, \mathbf{p}, \mathbf{t})$, o conteúdo da sentença (9) é o mesmo que o da sentença:

(9p) David Kaplan está em Portland em 26 de Março de 1977.

Mas enquanto a sentença (9) parece ser universalmente verdadeira, (9p) é contingentemente verdadeira (KAPLAN, 1989, p. 508-509). A solução encontrada por Kaplan para esse problema foi primeiramente apresentada em seu artigo On the Logic of Demonstratives.

Nesse artigo, Kaplan defende que os predicados e as funções devem ser duplamente indexados. Assim, enquanto na Linguagem de Primeira Ordem com Igualdade temos predicados n-ários e funções n-ária, ${ }^{23}$ na Linguagem dos Demonstrativos teremos predicados m-n-ários e funções m-n-árias. (KAPLAN, 1979, p. 87)

Semanticamente, um predicado $\mathbf{P}$ é interpretado como uma função em que, dado um certo mundo $\mathbf{w}$ e um certo instante de tempo $\mathbf{t}$, temos o conjunto dos indivíduos que têm a propriedade expressa por $\mathbf{P}$ naquele mundo $\mathbf{w}$ e naquele instante de tempo t. Já as funções se dividem em individuais e posicionais. No caso das funções individuais, elas são interpretadas como funções que levam indivíduos e posições em indivíduos. No caso das funções posicio-

\footnotetext{
${ }^{23}$ Por exemplo, o predicado "x é mortal" é unário, enquanto o predicado "x é discípulo de y" é binário; a função "a mãe de x" é unária, enquanto a função "o filho mais velho de $\mathbf{x}$ e $\mathbf{y}$ " é binária.
} 
nais, elas são interpretadas como funções que levam indivíduos e posições em posições. (KAPLAN, 1979, p. 88-89)

Para ilustrar tal semântica, retomemos o problema da referência do termo singular "o atual rei da França". Na semântica formal acima exposta, estamos diante de uma função individual o_rei_da_França(x). Dado um contexto (w, x, p, t), a função o_rei_da_França(x) aponta o indivíduo que é rei da França naquele contexto, caso haja um. Caso não haja nenhum rei na França naquele contexto, a função retorna como valor o símbolo arbitrário $†$.

Daqui, podemos inferir que a filosofia da linguagem de Kaplan é um reflexo bastante fiel da sua linguagem formal dos demonstrativos e sua semântica formal dos demonstrativos. Aqui, estamos claramente diante de um filósofo que vê a linguagem humana como uma maquinaria complexa, de modo que sua semântica formal captaria o funcionamento da linguagem natural. Podemos, nesse sentido, colocar Kaplan no mesmo grupo de Russell e Kripke, como fizemos na introdução deste artigo.

Mas o leitor atento pode ter se dado conta que, em vez de colocarmos a Lógica dos Demonstrativos como a lógica de Kaplan na tabela da introdução, colocamos a Lógica Híbrida em seu lugar. De fato, a Lógica dos Demonstrativos contém uma semântica formal e uma linguagem formal que, como vimos, é bem fidedigna à filosofia da linguagem de Kaplan. Mas em nenhum de seus trabalhos Kaplan apresenta um sistema de prova para essa semântica (com regras e axiomas) e, muito menos, prova algo semelhante ao Teorema de Completude que Kripke provou para a Lógica Modal de Primeira Ordem.

O ponto aqui é sabermos em que medida podemos considerar como lógica uma linguagem formal e semântica formal sem um conjunto de regras e axiomas, ou seja, sem um sistema dedutivo completo com relação a essa semântica. Em Filosofia das Lógicas, a filósofa Haack expõe que, de acordo com Kneale e outros lógicos, para um sistema formal ser considerado uma lógica, ele precisa ser completo com relação a uma certa semântica (KNEALE, 1961, p. 258-259 apud HAACK, p. 32). A filósofa, por sua vez, argumenta que esse critério "formal" de Kneale não é adequado, visto que a incompletu- 
de da teoria de conjuntos mostraria que o conceito de "pertinência" não pode ser caracterizado por um conjunto de axiomas e regras.

Ainda que o critério de Kneale possa não ser unânime para decidir se um sistema de prova ou uma semântica formal é ou não uma lógica, usarei aqui tal critério para distinguir lógica formal em sentido lato de lógica formal em sentido estrito. Em sentido lato, lógica formal pode ser tanto sinônimo de uma certa semântica formal quanto de um sistema de prova. Em sentido estrito, lógica formal consiste de uma semântica formal, um sistema de prova e um Teorema de Completude, que garante que são sempre verdadeiros semanticamente os teoremas provados no sistema, e apenas tais teoremas.

Em sentido lato, a lógica dos demonstrativos de Kaplan é claramente uma lógica dos indexicais. Ou seja, tal "lógica" consiste (apenas) de uma semântica formal que procura apreender a filosofia da linguagem de Kaplan. Mas seria possível uma lógica dos indexicais em sentido estrito? Acredito que esse é justamente o caso da lógica híbrida, como argumentarei a seguir.

\subsection{Lógica Híbrida: a Lógica dos Indexicais em Sentido Estrito}

Numa lógica modal, a função de verdade atribui um valor de verdade a uma dada proposição p e um mundo possível w. Isso significa que a verdade é relativa a cada mundo específico w. Para obter uma linguagem modal formal, normalmente acrescenta-se a uma linguagem formal apenas o operador modal de necessidade, definindo-se, por meio da negação e da necessidade, o operador de possibilidade. ${ }^{24}$ (BRAÜNER, 2020)

Como exemplo do problema de expressividade da lógica modal, retomemos a sentença (5). A princípio, podemos tomar os mundos possíveis como instantes de tempo t, t', t" e assim por diante. ${ }^{25}$ Assim, a sentença (5) poderia ser representada modalmente como:

\footnotetext{
${ }^{24}$ Essa é apenas uma maneira de definir uma linguagem modal formal. Outra maneira de definir uma linguagem modal formal equivalente é tomar o operador de possibilidade como primitivo e definir o operador de necessidade. Assim, dada uma proposição "p”, a operação “é necessário p" seria equivalente, por definição, a "não é possível não-p".

25 Nessa interpretação, os operadores modais são compreendidos de modo distinto. Aqui, "p é necessário" seria o mesmo que "em todos os instantes de tempo", ou simplesmente, "sempre". Já "p é possível" seria o mesmo que "em algum instante de tempo", ou simplesmente, "alguma vez".
} 
(5t) O rei da França no instante t é sábio.

O ponto aqui é que a linguagem modal pode apenas expressar que o rei da França é sábio em todos os instantes de tempo ou em ao menos um instante de tempo indeterminado. Não é possível, porém, expressar nessa linguagem um certo instante de tempo específico, que seria, por exemplo, o ano de 1905 .

Foi com essa intenção que Gargov e Goranko propuseram, em seu artigo Modal Logic with Names, enriquecer a linguagem modal com aquilo que denominaram constantes modais ou simplesmente nomes (names). Na linguagem formal proposta pelos autores, essas constantes modais são consideradas fórmulas atômicas, semelhantemente às variáveis proposicionais. Além disso, acrescenta-se um operador modal universal à linguagem. Semanticamente, interpreta-se as contantes modal do seguinte modo: acrescenta-se aos modelos de Kripke uma função que, a cada constante modal, atribui-se um mundo específico do conjunto de mundos possíveis. Cabe ressaltar que há uma diferença importante entre constantes modais e variáveis proposicionais: enquanto o valor semântico de uma variável proposicional pode ser entendido como um conjunto de mundos possíveis em que a proposição é verdadeira, o valor semântico de uma constante modal é um único mundo possível. Já o operador modal de necessidade universal é interpretado do ponto de vista semântico analogamente a um quantificador universal que, em vez de percorrer o domínio de objetos, percorre o domínio de mundos possíveis. ${ }^{26}$ (GARGOV e GORANKO, 1993, p. 610-611)

Mas será que essa linguagem híbrida consegue formalizar o indexical "atual" em (5)? Para isso, basta tomar uma constante modal a como contrapartida formal de um instante de tempo específico, por exemplo o ano de

\footnotetext{
${ }^{26}$ O leitor pode estar se perguntando qual seria a diferença entre o operador de necessidade kripkeano e o operador de necessidade universal, proposto por Gargov e Goranko. Vimo que operador de necessidade de Kripke é interpretado de modo que "necessário p" é verdadeiro num mundo $\mathbf{w}$ quando $\mathbf{p}$ é verdadeiro em todos os mundos possíveis w' acessíveis a w. Já "necessário universalmente p" é verdadeiro quando p é verdadeiro em todos os mundos possíveis w', independentemente de serem ou não acessíveis a w. Apenas no sistema S5, em que a relação de acessibilidade entre os mundos é universal, que os operadores de necessidade e de necessidade universal se colapsam.
} 
1905. Desse modo, conseguimos expressar nessa linguagem formal que o rei da França é sábio no ano de 1905, o que não conseguiríamos fazer na linguagem modal de Kripke.

A diferença principal entre essa abordagem e a "lógica" de Kaplan é que estamos diante de uma lógica muito mais madura. Na Seção 5 do artigo, os autores apresentam um sistema de prova com regras e axiomas (GARGOV e GORANKO, 1993, p. 622), demonstrando na Subseção 5.3 a completude desse sistema com relação à semântica anteriormente apresentada (GARGOV e GORANKO, 1993, p. 625-628).

Evidentemente, o sistema de Gargov e Goranko é muito mais rudimentar do que a semântica de Kaplan, pois a quádrupla $(\mathbf{w}, \mathbf{x}, \mathbf{p}, \mathbf{t})$ foi reduzida a um único mundo w. Mas não é nada muito complexo obter axiomas e uma semântica adequada para um sistema em que há quatro tipos de constantes modais: para mundos possíveis, para agentes, para posições e para instantes.

Outro ponto a enfatizar quanto à pobreza expressiva do sistema de Gargov e Goranko é que ele é proposicional enquanto que a filosofia da linguagem de Kaplan é claramente de primeira ordem. Numa linguagem proposicional, não há variáveis para indivíduos, apenas para proposições enquanto que, como vimos, numa Linguagem de Primeira Ordem há variáveis para termos gerais e para termos singulares. Assim, o problema do termo singular "o rei da França" se referir a indivíduos distintos em instantes de tempo distintos sequer pode ser colocado no sistema de Gargov e Goranko.

Mas não há nenhuma dificuldade adicional em estender os resultados de Gargov e Goranko para uma Lógica Híbrida de Primeira Ordem. Na verdade, Braüner foi o primeiro a propor uma Linguagem Híbrida de Primeira Ordem. Essa linguagem é uma expansão da Linguagem Modal de Primeira Ordem em que acrescentam-se: (i) variáveis para constantes modais; (ii) variáveis para descrições definidas; (iii) um operador unário para "o único indivíduo i em a”, tal que a é um nome para o certo mundo w. Além disso, nessa linguagem há um novo quantificador, denominado aglutinante (binder). Se a é um nome para o mundo $\mathbf{w}$, podemos expressar por meio desse quantificador 
algo como "a extensão do predicado $\mathbf{P}$ no mundo de nome a" (BRAÜNER, 2011, p. 129-131). Na mesma obra, Braüner propõe como sistema de prova um sistema de Dedução Natural para Lógica Híbrida de Primeira Ordem (2011, p. 139-140), demonstrando o Teorema de Completude com relação a essa lógica (2011, p. 143-149).

\section{Considerações Finais}

A Lógica Híbrida de Primeira Ordem de Braüner é construída por meio de uma linguagem formal bastante complexa. Essa linguagem captura conceitos modais como necessário e possível, bem como a distinção entre nomes próprios e descrições definidas. Além disso, tal linguagem é rica o suficiente para expressar algo do tipo "no nosso mundo atual". Assim, um termo singular como "o atual rei da França" pode ser expresso nessa linguagem como “o indivíduo denotado pela descrição definida 'o único rei da França' no mundo denotado por a”.

Porém, vimos na Seção 3 que, para Strawson, há mundos em que “o atual rei da França” não denota ninguém. Para isso, precisamos de uma lógica livre, ou seja, uma lógica que não respeita P2. Dito de outro modo, precisamos uma lógica em que nem todo termo singular se refere a um único objeto.

Vimos também, na mesma Seção 3, que se numa sentença a expressão "o atual rei da França" não tem referência, então, para Strawson, a sentença como um todo não será nem verdadeira nem falsa. Desse modo, a lógica da filosofia da linguagem de Strawson parece, como a de Frege, não respeitar P1 mas respeitar PC. Além disso, vimos na Subseção 1.1 que a lógica livre de Lehmann, denominada NINO, é justamente uma lógica que não respeita $\mathbf{P 1}$ e P2, mas respeita PC. O problema, como apontamos na Seção 3.1, é como interpretar formalmente em NINO o termo "atual". Mas é justamente aqui que entra em cena a Lógica Híbrida de Primeira Ordem de Braüner.

Vejamos então como interpretar a filosofia da linguagem de Strawson numa combinação entre a lógica de Lehmann e a lógica de Braüner. Na lógica em questão, a sentença (5) poderia ser expressa como: 
(5h) "O rei da França no mundo a é sábio".

Seja $\mathbf{w}$ nosso mundo atual tal que o nome de $\mathbf{w}$ é $\mathbf{a}$. Seja $\mathbf{P}$ o predicado unário "x é sábio" e i o termo individual para "o rei da França". Como não há um rei da França, o termo i não se refere a ninguém no mundo w. Portanto, a sentença (5h) não será nem verdadeira nem falsa.

Agora, suponhamos que a seja um nome de um outro mundo diferente do nosso, o mundo w'. Nesse mundo, o termo i se refere a Luís XIV tal que o indivíduo Luís XIV está na extensão no predicado “x é um sábio”. Logo, nesse mundo w', a sentença $(5 \mathrm{~h})$ será verdeira.

Por fim, consideremos que a é o nome de um terceiro mundo diferente dos outros dois, o mundo w". Nesse mundo, o termo i se refere a Luís XV tal que o indivíduo Luís XV não está na extensão no predicado "x é um sábio". Logo, nesse mundo w" a sentença (5h) será falsa.

Por essas razões, acredito que uma combinação da lógica híbrida de Braüner com a lógica NINO de Lehmann seria muito mais próxima da filosofia da lingugem de Strawson do que as duas opções apresentadas na Subseção 3.1: a de Caorsi e a de van Fraassen.

\subsection{Por uma Lógica Híbrida Livre de Quatros Valores}

Ainda que uma combinação da lógica híbrida de Braüner com a lógica NINO possa resolver em grande medida os problemas concernentes aos termos singulares que foram abordados nesse artigo, ela não dá conta da seguinte questão. Retomemos as sentenças abaixo:

(2) Ulisses desembarcou em Ítaca;

(3) Ulisses não desembarcou em Ítaca.

Como apontado por Orlando em seu artigo Fictional Names without Fictional Objects, uma perspectiva que oferece um modelo para a sentença (2) ser verdadeira - como na lógica livre positiva - é tão anti-intuitiva como outra 
que infere que a sentença (3) é verdadeira - como na lógica livre negativa (ORLANDO, 2008, p. 118). Poderíamos acrescentar ainda que uma perspectiva que infere que é consistente sustentar, ao mesmo tempo, (2) e (3) também seria bastante anti-intuitiva, que é justamente o que diz tanto a lógica livre de Lehmann quanto a lógica livre de Bencivenga.

Para superar esse dilema, proponho distinguir dois níveis de verdade: verdades ficcionais e verdades reais. Acredito que tal lógica da filosofia da linguagem consiste numa lógica livre de quatro valores. Considerando que o termo ficcional "Ulisses" não tem referência, a sentença (2) como um todo deve ser ficcionalmente verdadeira e a sentença (3) deve ser ficcionalmente falsa. Podemos generalizar essa ideia para quaisquer nomes ficcionais, de modo que teremos quatro valores: verdadeiro realmente, verdadeiro ficcionalmente, falso ficcionalmente e falso realmente.

É digno de nota que essa lógica, diferentemente das lógicas livres existentes na literatura, respeitaria $\mathbf{P 1}$ de um modo mais fraco, a saber: toda sentença seria verdadeira (realmente ou ficcionalmente) ou falsa (realmente ou ficcionalmente), não podendo ser atribuído a cada sentença mais de um valor de verdade ou nenhum. Por outro lado, essa lógica respeitaria a condição de Strawson também num sentido mais fraco: em contextos ficcionais, a verdade real ou a falsidade real de uma sentença não seria colocada, ainda que pudesse ser colocada a questão da verdade ou falsidade ficcional da sentença.

Por fim, combinando uma lógica livre de quatro valores com a lógica híbrida de Broüner, podemos ter uma linguagem rica o suficiente para, em grande medida, acomodar também as modalidades de Kripke e os indexicais de Kaplan. Por essas razões, acredito que a filosofia da linguagem que emergisse dessa lógica seria capaz de propor um modelo que abarcasse as considerações de Frege, Russell, Strawson, Kripke e Kaplan sobre os termos singulares. Além disso, tal lógica passaria incólume às críticas apontadas por Orlando às lógicas livres existentes na literatura.

Não quero dizer que minha proposta de uma lógica híbrida livre de quatro valores seria a solução definitiva para o problema dos termos singulares 
na linguagem natural. Simplesmente porque - parodiando Strawson - a lógica exata dos termos singulares na linguagem natural simplesmente não existe.

\section{Agradecimentos}

Essa pesquisa foi possível graças ao financiamento institucional da UFFS (Universidade Federal da Fronteira Sul) por meio do Projeto PES2019-0591 intitulado "Nomes próprios e os limites das teorias referenciais da linguagem".

Agradeço a leitura atenta do parecerista anônimo da revista, o que permitiu que a versão final do artigo tivesse uma versão muito mais apresentável que a original. Também agradeço a leitura cuidadosa dos discentes Derócio Felipe Perondi Meotti (UFFS) e Nathalia Rodrigues da Costa (Unicamp) que, mesmo não sendo estudiosos em lógica, revisaram o artigo minuciosamente. Agradeço, finalmente, os demais colegas, docentes e discentes, membros do Grupo de Pesquisa em Lógica, Linguagem e Conhecimento da UFFS que tiveram o trabalho de ler versões prévias desse texto, com comentários e observações gerais.

\section{Referências}

ARISTÓTELES, "De Interpretatione", trad. J. L. Ackrill, em: ROSS, D. (ed.), The Complete Works of Aristotle, Princeton: Princenton University Press, 1991.

, "Prior Analytics", trad. A. J. Jenkinson, em: ROSS, D. (ed.), The Complete Works of Aristotle, Princeton: Princenton University Press, 1991.

BENCIVENGA, E , "Free Logics," em: GABBAY, D. e GUENTHNER, F. (eds.), Handbook of Philosophical Logic, vol. III: Alternatives to Classical Logic, Dordrecht: D. Reidel, 1986.

BRAÜNER, T., Hybrid Logic and its Proof-Theory, em: "Applied Logic Series": Volume 37, Dordrecht-Heidelberg-Berlin-New York: Springer, 2011.

, "Hybrid Logic", em: The Stanford Encyclopedia of Philo-

sophy, ZALTA, E. N. (ed.) Disponível em: https://plato.stanford.edu/entries/logic-hybrid/ ,11 de julho de 2020. 
CAORSI, C. E. "Referência e termos singulares", trad. Itamar Luís Gelain, em: CONTE, J. (ed.), Ensaios Sobre a Filosofia de Strawson, Florianópolis: UFSC, 2015.

DONNELLAN, K., "Reference and Definite Descriptions", em: Philosophical Review, v. 75, 1966, p. 281-304.

FREGE, G., "Digressões sobre Sentido e Referência" em: Lógica e Filosofia da Linguagem. 2. ed. revista e ampliada. Seleção e trad. de Paulo Alcoforado. São Paulo: EDUSP, 2009.

Fundamentos da Aritmética, em: "Coleção Os Pensadores", vol. XXVI, trad. Luiz Henrique dos Santos, São Paulo: Abril Cultural, 1974.

, "O Pensamento. Uma Investigação Lógica", em: Investigações Lógicas. Org., trad. e notas de Paulo Alcoforado, Porto Alegre, EDIPUCRS, 2002.

Os Primeiros Escritos Lógicos de Gottlob Frege, tradução de P. Alcoforado,A. Duarte e G. Wyllie,. São Paulo: Instituto Brasileiro de Filosofia e Ciência Raimundo Lulio, 2012.

"Sentido e Referência" em: Lógica e Filosofia da Linguagem.

2. ed. revista e ampliada. Seleção e trad. de Paulo Alcoforado. São Paulo: EDUSP, 2009.

"Sobre a Justificação Científica de uma Conceitografia" em: Lógica e Filosofia da Linguagem. 2. ed. revista e ampliada. Seleção e trad. de Paulo Alcoforado. São Paulo: EDUSP, 2009.

GARGOV, G., GORANKO, V., "Modal Logic with Names", Journal of Philosophical Logic, vol. 22, 1993, p. 607-636.

HAACK, S. Filosofia das Lógicas. Tradução de César Augusto Mortari. São Paulo: Unesp, 2002.

HEGENBERG, L. Lógica, Rio de Janeiro, RJ: Editora Forense Universitária, 2012.

KAPLAN, D. "Demonstratives: An Essay on the Semantics, Logic, Metaphysics, and Epistemology of Demonstratives and Other Indexicals" em: PERRY A., J., WETTSTEIN, H., Themes from Kaplan, Oxford: Oxford University Press, 1989.

, "On the Logic of Demonstratives", em: Journal of Philosophical Logic, vol. 8, n. 1, janeiro de 1979, p. 81-98. 
KNEALE, W.C., "The Province of Logic", em: Contemporary British Philosophy, Lewis (ed.), série 3, 2a edição, Allen and Unwin, 1961.

KRIPKE, S., O Nomear e a Necessidade, trad. Ricardo Santos e Teresa Filipe, Lisboa: Gradiva, 2012.

, "A Completeness Theorem in Modal Logic", em: The Journal of Symbolic Logic, v. 24, n. 1, março de 1959., p. 1-14.

"Semantical Analysis of Modal Logic I. Normal Modal Propositional Calculi”, em: Zeitschrift für Mathematische Logik und Grundlagen der Mathematik, v. 9, n. 5-6: 67-96, 1963.

"Semantical Analysis of Modal Logic II. Non-normal Modal Propositional Calculi", em: ADDISON, J.W.; HENKIN, L.; TARSKI, A. (eds.), Symposium on the Theory of Models, Amsterdam: North-Holland, 1965.

LEHMANN, S., "Strict Fregean Free Logic", em: Journal of Philosophical Logic, v. 23 n. 3: 307-336, 1994.

MORRIS, M, An introduction to Philosophy of Language, Cambridge: Cambridge University Press, New York, NY, 2007. 326 p.

MORTARI, C. A., Introdução à Lógica. 2 ed., São Paulo: Unesp, 2016. 525 p.

NOLT, J., "Free Logic", em: The Stanford Encyclopedia of Philosophy, ZALTA, E. N. (ed.) Disponível em: https://plato.stanford.edu/archives/ fall2018/entries/logic-free/, 11 de julho de 2020.

ORLANDO, L., "Fictional Names without Fictional Objects", em: Revista Hispanoamericana de Filosofía, vol. 40, n. 120, p. 111-127.

RUSSELL, B., A Filosofia do Atomismo Lógico, em: "Coleção Os Pensadores", vol. XLII, trad. Pablo Rubén Mariconda, São Paulo: Abril Cultural, 1974a.

Da Denotação, em: "Coleção Os Pensadores", vol. XLII, trad. Pablo Rubén Mariconda, São Paulo: Abril Cultural, 1974b

, Introdução à Filosofia Matemática, trad. Maria Luíza X. de A. Borges, Rio de Janeiro : Jorge Jahar, 1996 "Mr. Strawson on Referring", em: Mind, vol. 66, n. 263, 1957, p. 385-389.

, “On Denoting”, em: Mind, vol. 14, 1905, p. 479-93. 
Almedina, 2001.

Os Problemas da Filosofia, trad. António Sérgio, Coimbra:

STRAWSON, P. F., “On Referring”,em: Mind, v. 59, 1950, p. 320-44.

, Sobre o Referir, em "Coleção Os Pensadores", vol. LII, trad. Balthazar Barbosa Filho, São Paulo: Abril Cultural, 1974.

"Réplica a Carlos C. Caorsi" em: CAORSI, C. C (ed.), Ensaios Sobre a Filosofia de Strawson com réplicas de P. F. Strawson, trad. Itamar Luís Gelain e Jaimir Conte, Ijuí: Ed. Unijuí, 2015.

SZABÓ, Z. G., "Compositionality", em: The Stanford Encyclopedia of Philosophy, ZALTA, E. N. (ed.). Disponível em: https://plato.stanford.edu/archives/sum2017/entries/compositionality/, 11 de julho de 2020.

van FRAASSEN, B. C., "Singular Terms, Truth Value Gaps and Free Logic," em: Journal of Philosophy, v. 63, n. 17, 1966, p. 481-95. 